\title{
A biomechanical model to assess the injury risk of leopards (Panthera pardus) hunting by free falling from trees
}

\section{Rudemar Ernesto Blanco and Daniel Eduardo Luzardo-Vera}

Instituto de Física, Facultad de Ciencias, Iguá 4225, Montevideo, 11400, Uruguay

Address correspondence and requests for materials to Rudemar Ernesto Blanco, ernesto@fisica.edu.uy

\begin{abstract}
Leopards have been observed to ambush prey by jumping down on it from trees. There are both anecdotal reports and video recordings of this hunting behavior. Here we conducted a biomechanical analysis of this technique to assess the degree of risk for the predator in such cases. We concluded that the risk of suffering severe injuries seems to be too high for this technique to be a usual way of predation on horned mammals such as male impalas. Our results can be useful in discussing proposed paleobiological hunting scenarios and living predators' strategies of managing risks.
\end{abstract}

Keywords: Panthera pardus, hunting risk, free-falling, hunting behavior, predator-prey interactions

\section{Introduction}

Leopards (Panthera pardus) hunt chiefly by stalking prey or by ambush, during which the animal uses the advantages of its covered habitat. The leopard may make a short, extraordinarily fast dash at its victim from the stalk or ambush position. It kills smaller prey by biting the nape of the neck or puncturing the skull with its canines, whereas larger prey is bitten on the throat, allowing the

Citation: Blanco, R. E. and LuzardoVera, D. E. 2021. A biomechanical model to assess the injury risk of leopards (Panthera pardus) hunting by free falling from trees. Bio. Comm. 66(3): 236-244. https://doi. org/10.21638/spbu03.2021.305

Authors' information: Rudemar Ernesto Blanco, PhD, Head of Laboratory, orcid. org/0000-0002-6317-2921; Daniel Eduardo Luzardo-Vera, Student, orcid.org/0000-00030148-9584

Manuscript Editor: Pavel Skutschas, Department of Vertebrate Zoology, Faculty of Biology, Saint Petersburg State University, Saint Petersburg, Russia

Received: December 7, 2020;

Revised: April 1, 2021;

Accepted: April 13, 2021.

Copyright: $\odot 2021$ Blanco and Luzardo-Vera. This is an open-access article distributed under the terms of the License Agreement with Saint Petersburg State University, which permits to the authors unrestricted distribution, and self-archiving free of charge.

Funding: PEDECIBA and ANII provided financial support.

Ethics statement: This paper does not contain any studies involving human participants or animals performed by any of the authors.

Competing interests: The authors have declared that no competing interests exist. leopard to avoid the horns and antlers of antelope and deer (Kruuk and Turner, 1967; Bothma and Le Riche, 1984; Bothma and Le Riche, 1989; Bothma, Van Rooyen and Le Riche, 1997; Stander, Haden, Kaqece and Ghau, 1997; Turner, 1997; Sunquist and Sunquist, 2002; Bailey, 2005; Jenny and Zuberbühler, 2005; Balme, Hunter and Slotow, 2007; Stein and Haysen, 2013). Additionally, there is evidence of leopards using flexible hunting strategy (Bothma and Le Riche, 1989), prey-specific hunting tactics (Bothma, Van Rooyen and Le Riche, 1997), and differences in the hunting behavior of forest leopards from that of savannah leopards (Jenny and Zuberbühler, 2005). Attempts only ended in kills in $5 \%$ of hunts in the Serengeti (Bertram, 1982), 16\% of hunts in the Kruger (Bailey, 2005), and $38 \%$ of hunts in Kaudom, Namibia (Stander, Haden, Kaqece and Ghau, 1997). Furthermore, between $5 \%$ and $10 \%$ of kills are lost to other predators, especially lions (Panthera leo) and spotted hyaenas (Crocuta crocuta) (Bailey, 2005). Leopards minimize kleptoparasitism by caching carcasses in trees, caves, and large burrows or by dragging them into dense vegetation (Sunquist and Sunquist, 2002).

There are some uses of trees for hunting behavior discussed in the literature (Kruuk and Turner, 1967; Hart, Katenbo and Punga, 1996; Sunquist and Sunquist, 2002 and references therein). Some species of primates are hunted in trees by leopards (Sunquist and Sunquist, 2002 and references therein). Leopards of the Ituri Forest in Zaire were observed patrolling fruiting trees known to be visited by duikers and bush pigs. Carcasses of prey were found in the vicinity of these trees as well (Hart, Katenbo and Punga, 1996). In the Serengeti area, twice a leopard was seen resting on a high branch of a tree when it perceived a reedbuck near the 
dense shrubbery below. It then came down the trunk, crept very slowly towards the reedbuck, and when it was very near, jumped at it, missing on one occasion (Kruuk and Turner, 1967).

There has not been much discussion of hunting by free falling from trees, which has been documented in some videos (Leopard - Cheetah Channel 2017, Kruger Sightings 2019, ACID 2018, Shock wave 2019, Shazal 2015) and anecdotally reported (Hunter, 1952). A well-studied analog is the diving hunting behavior of predatory birds. Sometimes falcons go to high altitudes and then descend from those heights, using gravity to increase their speed. Maximum hunt speeds in a dive are largely variable based on the duration of the dive, acceleration before the dive, and the steepness of the dive, but values greater than $100 \mathrm{~km} / \mathrm{h}$ have been recorded (Hart, Wreford, Brown and Downs, 2018). Falco peregrinus may exceed $200 \mathrm{~km} / \mathrm{h}$ (Tucker, Cade and Tucker, 1998; Hart, Wreford, Brown and Downs, 2018).

Falcons presumably approach prey at a speed that balances the risk of injuring themselves against the risk of failing to catch prey; this should favor lower speeds than the maximum theoretically available in a dive (Tucker, Cade and Tucker, 1998; Tucker, 1998). Although the falcon's speed is much higher than that of leopards, the birds can control their speed in a dive by changing their drag and choosing the length of the dive (Tucker, 1998). Compared to falcons, the aerodynamic forces on the free-falling leopards are very small, since there is not much control of the speed and direction after losing contact with the tree (Vogel, 2009). This behavior seems highly risky due to accidental collisions at high speed and without many possibilities of making adjustments to the speed and direction. Therefore, it is expected that this behavior occurs only sporadically.

In leopards, free-falling over prey such as male impalas implies an injury risk due to a misplaced collision of the leopard's chest or head against the impala's back or horns. Injuries have been relatively well studied in raptors and carnivores and can be fairly common (Mukherjee and Heithaus, 2013). Dislocation of joints (Ackermann and Redig, 1997) and broken toes, talons, flight feathers, and injured eyes are widely documented in raptors (Mukherjee and Heithaus, 2013). In Canada, 5.9\% of American kestrels had hunting-related injuries (Murza, Bortolotti and Dawson, 2000), 14\% of 98 individuals of raptors in northern Arkansas had injuries (Bedrosian and Pierre, 2007). Inspection of museum specimens of Accipiter hawks revealed that $18.6 \%$ of 339 individuals had hunting injuries (Roth, Jones and French, 2002). High rates of fractured canines were recorded for some species of the order Carnivora. For representatives of the genus Panthera, the values are $5.4 \%$ for lions (Panthera leo), 9.2\% for tigers (Panthera tigris), and $9.8 \%$ for leopards (Panthera pardus) (Table 3 in Van Valkenburgh,
2009). The observed breakage rates are likely to be due to injuries sustained by moving and struggling prey during hunting (Van Valkenburgh and Hertel, 1993). Few data are available for the proportion of individuals injured by prey in soft tissues or other parts of the body. Such injuries are known to occur; for example, African wild dogs may incur deep cuts, broken teeth, and injured limbs (Creel and Creel, 2002).

It has been highlighted that it will be a challenge to quantify the risks of injury in the wild. The collection of such data in situations where there are changes in prey availability that might affect willingness to take risks or invasions of potentially dangerous prey should be an important avenue of future research for behavioral ecologists (Mukherjee and Heithaus, 2013). The study of skeletal-injury frequency and distribution is an interesting clue for paleobiological inferences of hunting behavior in predatory vertebrates (Brown, Balisi, Shaw and Van Valkenburgh, 2017; Van Valkenburgh, 2009; Van Valkenburgh and Hertel, 1993). Moreover, the biomechanical evaluation of injury risks derived from hunting behaviors is useful for discussing paleobiological hunting scenarios (Farlow, Smith and Robinson, 1995; Krauss and Robinson, 2013).

Here we applied a biomechanical model (Sturdivan, Viano and Champion, 2004; Frank et al., 2011) to assess the leopard's risk of injury while performing free-falling hunting. Similar approaches were already attempted in paleontological studies of predator-prey interaction (Krauss and Robinson, 2013). We also discussed some implications of our results for the general understanding of predator's risk of injury management and paleobiological inferences.

\section{Material and methods}

\section{Collision analysis}

In the analyzed situation, an inelastic collision is observed in a hunting situation where a leopard jumps from a tree and hits an impala. The leopard carries the initial mechanical energy in kinetic form during the fall. This energy is partially transmitted on impact, modifying the kinetic energy of both animals. An amount of this initial energy is dispersed in the form of sounds, heat, and mainly dangerous deformations of biological tissues for both specimens. This released energy will be called $Q$, and it is of vital importance when evaluating risks or possible damage to both prey and predator. Considering that the initial speed of the impala is zero, the following expression is reached for the energy released in the shock:

$$
Q=K_{i}\left(1-\left(\frac{e^{2}+v}{1+v}\right)\right),
$$


where $e$ is the coefficient of restitution, $K_{i}$ is the initial kinetic energy of the free-falling leopard, and $v$ is the ratio of the masses $m$ of the leopard and $M$ of the impala $(v=m / M)$. For the case of interest, where the leopard falls clinging to its prey, the shock can be modeled as a perfectly inelastic collision, and equation (1) will transform into:

$$
Q=K_{i}\left(\frac{1}{1+v}\right)
$$

This energy is a fraction of the initial one and will be available, to a greater extent, to cause damage to the biological tissues involved, as long as the leopard directly impacts the impala. However, this does not usually happen since the leopard has a significant amount of muscle mass in its strong forelimbs with which it absorbs part of the energy. This capacity of muscle to absorb energy during forced stretching is estimated by using the following equation:

$$
\sigma \cdot \varepsilon=\frac{F}{A} \cdot \frac{\Delta l}{l}=\frac{W}{V}
$$

where $l$ is the muscle length, $\Delta l$ is the length variation of the muscle, $A$ is the muscle cross-section area, $V$ is the muscle volume, and $W$ is the work involved in forced stretching of the muscle. The maximum stress of rat leg muscles measured experimentally is close to $\sigma=$ $300 \mathrm{kPa}$, and the maximum deformation is around $\varepsilon=$ 0.25 (Alexander, 2003). Equation (3) predicts an energy absorption capacity of $75 \mathrm{~J}$ per kilogram of muscle mass. All these are typical values for vertebrate striated muscle (Alexander, 2003 and references therein). The main muscle groups that the leopard comprises by absorbing energy from its fall on the impala are the pectorals, triceps, manus extensors, and deltoids. In the literature, there is no precise data about the mass of these muscles in P.pardus, so the information available from a different species of similar body mass (Panthera uncia) was used instead, which is considered the best available approximation (Cuff et al., 2016). The snow leopard (P. uncia) is different in hunting strategy and body proportions (including forelimb weight) to the leopard (P.pardus); therefore, the inaccuracies derived from this approximation were tackled by performing a sensitivity analysis with considerable variations $(33 \%)$ on the mass of the muscles. The muscles in each leg involved in absorbing energy from its fall add $1.490 \mathrm{~kg}$ of muscle mass for a female P. uncia of $36 \mathrm{~kg}$ (Cuff et al., 2016). Assuming a similar value for $P$. pardus, we estimated that it could absorb $112 \mathrm{~J}$ of energy with its front legs before impacting with its chest on the loin of the prey, as the studied videos show. This implies that the following equation gives the energy available to cause damage:

$$
Q_{e f}=Q-112 \mathrm{~J} .
$$

After the contact of forelegs against the impala, the leopard continues falling and strikes the impala's body with the chest or head. We modeled these kinds of collisions between the chest or head of the leopard against the back or head of the impala. The energy available was assumed as in equation (4).

\section{Data analysis}

Five videos showing leopards hunting impalas by free falling from trees were collected (Leopard - Cheetah Channel 2017, Kruger Sightings 2019, ACID 2018, Shock wave 2019, Shazal 2015) and analyzed with the software Tracker 5.1.5 (Open Source Physics). The objects were manually tracked due to poor automatic discernment between objects and background. The tip of the snout of the leopard was chosen as the point of mass. To estimate the scale, we used the average body length of a leopard in two cases (Leopard - Cheetah Channel 2017, Kruger Sightings 2019) and the average shoulder height of an impala in the other three (ACID 2018, Shock wave 2019, Shazal 2015). The average shoulder height is $86.1 \mathrm{~cm}$ for impala, and the average body mass is $48.75 \mathrm{~kg}$ (Frey et al., 2019). For a female leopard, the average body and head length is $106.5 \mathrm{~cm}$ (Stein and Hayssen, 2013). We took this value, corresponding to a female because we have accurate data of the mass of forelimb muscles for a female specimen of $P$. uncia with a body mass of $36 \mathrm{~kg}$ (Cuff et al., 2016). The typical body mass values for female P.pardus are consistent with this value (Stein and Hayssen, 2013).

From the videos, all the height values from which the predator falls were rather similar (Appendix 1), with variations within the errors due to the uncertainties in the scale choice. For that reason, we preferred to use the average height value of $3.55 \mathrm{~m}$ and consider the variations and uncertainties in a sensitivity analysis. Therefore, the typical distance of free-falling before the collision was considered as $2.69 \mathrm{~m}$. The initial vertical speed is negligible in all cases. Hence, the initial mechanical energy is equal to the gravitational potential energy of the leopard. Therefore, considering the initial height of the leopard's center of mass minus the impala's height at shoulder, and using the data of the masses, the value of $Q$ given by equation (2) is $545.7 \mathrm{~J}$. Accordingly, equation (4) provides that $Q_{e f}=433.9 \mathrm{~J}$. There would be a second impact, from the impala's shoulder height to the ground, where the leopard could also use the hindlimbs to absorb the residual kinetic energy. This fall would probably not suppose a much greater risk to the leopard, and it was neglected in our analysis. 
Injury risk assessment using the Blunt Criterion modified ( $\mathrm{BCm})$

The Blunt Criterion parameter (Sturdivan, Viano and Champion, 2004) used to predict injury risk is defined by the following equation:

$$
B C=\ln \left(\frac{E}{m^{(1 / 3)} T D}\right),
$$

where $m^{1 / 3}$ is the cubic root of the mass of the struck body, with the mass in kilograms, $E$ is the kinetic energy of the projectile in meters per seconds, $T$ is the thickness of the body wall at the impact location on the individu$\mathrm{al}$, and $D$ is the diameter, in centimeters, for the impact area. The numerator in equation (5) represents the energy available to cause damage. The previously estimated energy $Q_{e f}$ is a good estimation for $E$ (Sturdivan, Viano and Champion, 2004). The denominator is a semiempirical expression of the animal's capacity to absorb and tolerate the energy of the impact. In this case, the evaluation of damage focuses on the leopard, who also contributed the initial kinetic energy. So, the BC criterion adapted for our case is:

$$
B C_{m}=\ln \left(\frac{Q_{e f}}{m^{(1 / 3)} T D}\right) .
$$

The chest wall thickness of predator $(T)$ was estimated based on the method of Sturdivan, Viano and Champion (2004), where $T=k \cdot m^{1 / 3}$. We choose 0.789 for the parameter $k$ : the value for dogs and the highest of the values available (Table 1 in Sturdivan, Viano and Champion, 2004).

The injury risks were assessed in four situations that range from a normal hunting situation to an extremely risky one. We considered the four combinations of the leopard's chest or head colliding accidentally against the back or the horn of the impala. The trauma of a forelimb would also be highly disadvantageous for survival. Therefore, the analysis for a forelimb would be interesting (both against the body and a horn). However, the methods used here were developed, refined, and experimentally tested only for chest and head collisions (Sturdivan, Viano and Champion, 2004; Frank et al., 2011). For general discussion, we assumed that forelimbs are biomechanically better suited to support collisions than the chest or head because the limbs are adapted for supporting high loads during jumping or running. It is highly likely that the risk evaluation of forelimbs injuries would be smaller than the other cases, and even if that is not the case, forelimbs injuries would not involve death in the short term.

The following values were used for calculating the modified Blunt Criterion: for collisions against a horn you must use only the mass of the head of the impala as
$M$. It was estimated as $M=8.4 \mathrm{~kg}$ by using a rough estimation of the volume from scaled images and considering a mean density of $1,000 \mathrm{~kg} / \mathrm{m}^{3}$. The estimated thickness of the soft tissue of the leopard's chest was $T=2.61 \mathrm{~cm}$. The diameters of the impact area $(D)$ against the back of the impala were estimated considering the chest's dimensions and the head of an average leopard from scaled photos. For a collision with the leopard chest against the back of the impala, the diameter was estimated as $D=32.7 \mathrm{~cm}$, and for a collision with the head of the leopard against the back of the impala, $D=16.0 \mathrm{~cm}$. For the leopard head, we considered a mass $\mathrm{m}=3.1 \mathrm{~kg}$ and a $\mathrm{T}$ value of $1.15 \mathrm{~cm}$. For collisions against the horn, we made the following considerations: When a small, blunt object hits the body, the area of contact is just the crosssectional area of the projectile. As the projectile size increases, the area of contact is determined by the curvature of the projectile and the body part struck. The effective diameter was calculated as the deformed surface of the skin by a cone of radius $0.4 \mathrm{~cm}$ (the diameter of the tip of impala's horn) and height equal to the distance $T$ that must penetrate before producing serious damage. These measurements were taken from images of a male impala's head scaled on software Tracker 5.1.5 (Open Source Physics). Therefore, for collisions against a horn, the obtained effective diameter value of $D=2.1 \mathrm{~cm}$ was considered.

\section{Probability of lethality and AIS scale}

The probability of lethal blunt trauma due to non-penetrating impact is given according to a multiparametric lethality model to estimate the probability of a nonpenetrating projectile causing lethal blunt trauma to the thorax. This model was based upon a compilation of empirical databases derived from live-animal tests (Sturdivan, Viano and Champion, 2004). The equation presented in the international metric system (MKS) is the following (Frank et al. 2011):

$$
P_{L}=\frac{1}{1+e^{\left(39.9192-3.597 \cdot \ln \left(\frac{Q_{e f}}{m^{(1 / 3)} T D}\right)\right)}} .
$$

The results are compared using the 1985 AIS scale (see Sturdivan, Viano and Champion, 2004; Frank et al., 2011; and references therein). The value of AIS corresponding to $B C_{m}$ values was obtained by a linear fit of the data presented in Sturdivan, Viano and Champion (2004).

To estimate errors due to uncertainties in the measurements and estimations of the model parameters we made, a sensitivity analysis was done, considering extreme variations in linear dimensions of $10 \%$. That 
Table 1. Results of the biomechanical model

\begin{tabular}{l|c|c|c}
\hline \multicolumn{1}{c|}{ Situation } & BC Value & Probability of lethal blunt trauma, \% & AIS estimated Value \\
\hline Leopard chest - Impala body & $0.43(-0.62-0.97)$ & $0.53(0.1-3.5)$ & $2.6(0.0-3.9)$ \\
\hline Leopard chest - Horn & $2.32(2.15-2.72)$ & $82.5(72.0-95.3)$ & $7.3(6.9-8.3)$ \\
\hline Leopard head - Impala body & $1.05(0.62-1.45)$ & $4.71(1.0-17,3)$ & $4.1(3.1-5.1)$ \\
\hline Leopard head - Horn & $3.66(3.13-4.07)$ & $99.8(98.9-99.9)$ & $10.6(9.3-11.7)$ \\
\hline
\end{tabular}

The errors estimated by the sensitivity analysis are shown between parenthesis.

implies extreme variations of $21 \%$ in areas and $33 \%$ in masses.

\section{Results}

The main results are shown in Table 1 . The probability of lethal blunt trauma seems to be relatively high even in the most usual situation of the leopard chest colliding against the impala body $(0.1-3.5 \%)$. In the case of an impact against a horn, it is almost certainly a fatal result (see Table 1). All this suggests that high accuracy in leopard movements is required to avoid lethal injuries, and this technique must be used only exceptionally. The leopard's average speed at the collision, after free-falling from $2.69 \mathrm{~m}$ height, is slightly larger than $7 \mathrm{~m} / \mathrm{s}$ (see Appendix 1 for detailed measurements for each video). The sensitivity analysis provided an estimated error in the results that are displayed in Table 1.

\section{Discussion}

From simple physics considerations and the measurements from video tracking (see Methods section and Appendix 1), we concluded that the time of the leopard's free-falling before collision is roughly $0.7 \mathrm{~s}$. If the impala's reaction time is around 0.1 or $0.2 \mathrm{~s}$ and the acceleration is close to $7 \mathrm{~m} / \mathrm{s}^{2}$ (Alexander, 2003), the time required to evade the collision is larger than the time available. Thus, free-falling hunting seems to be highly successful if the prey does not detect the stalking leopard in advance. However, the estimated risk of injury during free falling hunting, between $0.1 \%$ and $3.5 \%$ in one of the better situations (see Table 1), seems too high for a predator like a leopard that must hunt at least once a week for several years (Schaller, 1972). The high associated risk may explain why this behavior has been only occasionally recorded, and that it is highly unusual in leopards and other large felids. Moreover, this behavior requires the ability to choose the right moment to initiate the free-falling. To miss the target would imply losing the prey, and falling over the horns would imply an extremely high risk of lethal injury. If we consider our biomechanical model, a collision between animals of similar body size produces the same probability of damage for both. In the case of a successful collision against the trunk of the impala, it is unlikely that the leopard produces lethal damage. Therefore, this hunting behavior seems to be suitable for bringing down or catching the prey, but the probability that the collision itself produces significant damage when hunting prey of similar size is very low (3.5\% at most). This observation is consistent with the fact that there is no video where the impala seems to be lethally injured only by the collision. The recorded free-falling hunting probably is only an unusual opportunistic behavior in leopards.

Another interesting observation is that the measured collision speed of around $7 \mathrm{~m} / \mathrm{s}$ is smaller than the maximum running speed of a charging leopard (Alexander, 2003). Therefore, the high risk involved in free-falling hunting is mostly due to the lack of control, but not due to the high collision speed. Crucial points seem to be the choice of prey and the timing of free falling to avoid a collision with horns. In three of the analyzed videos, the prey were females or juveniles (ACID 2018, Shock wave 2019, Shazal 2015), which would indicate that the leopards prefer to avoid the possible damage caused by the horns of the male impala, making this hunting strategy safer. Although, presumably under pressure from scarcity conditions or opportunism, attacks on males were also observed in two of the analyzed videos (Leopard Cheetah Channel 2017, Kruger Sightings 2019). Moreover, the two attacks on horned males seem to be from a lower height than all the others. In one of those hunts (Kruger Sightings, 2019), the leopard slightly changed its direction by pushing its limbs against the tree. When attacking horned prey, leopards are probably more cautious and prefer lower heights and increased control to reduce the risks. The low variation in height probably results from a tradeoff between being undetected and maintaining a low value of the injury risk. Leopards seem to have difficulties handling free falls from a height larger than 4 or 5 meters since no heights above this level were observed in the studied videos. However, due to the small number of videos analyzed, all our suggestions about impala sex and age preferences and prevalence conclusions are highly speculative, and further observations are needed to test these issues. 
The methods proposed here can be useful to study some paleobiological scenarios involving collisions between predators and prey or during intraspecific fighting. For example, it was proposed that pachycephalosaurs' domed skulls were adaptations for head butting behavior (Galton, 1971). However, the hypothesis of agonistic head-to-head butting was considered questionable because the small contact area of opposing heads would produce serious injuries (Alexander, 1989). Instead, flank-butting was suggested based on the analogy with extant African antelopes, and it was suggested that this kind of behavior would produce pain in the opponent without causing serious injuries (Carpenter 1997). The methods presented here could be helpful to compare both hypotheses. For Tyrannosaurus rex a hunting scenario was proposed involving collisions with heavy prey such as Triceratops (Krauss and Robinson, 2013) that can be evaluated in depth by using the methods to determine lethal blunt trauma. The Miocene sabretooth borhyaenoid Thylacosmilus atrox (Riggs, 1934; Goin and Pascual, 1987) also presents as a unique feature a domed skull, formed by the enlarged maxillary bones that house the upper canines (Janis et al., 2020). The maxillae of T.atrox are extensively pitted and grooved in all specimens, suggestive of some particular soft tissue covering (Janis et al., 2020), and a corneous covering was proposed (Riggs, 1934). These and other anatomical features could lead to the highly speculative hypothesis that T. atrox used head butting against prey or conspecifics (Francisco Goin, personal communication, May $18^{\text {th }}$, 1996). The head-butting hypothesis can be tested considering the risk of injuries of such behavior. Traumatic injuries directed to the neck, chest, and back (compression of vertebrae, compression stress fractures of limb bones, and dislocations) in Smilodon suggest violent and powerful contact with heavy prey (Turner, 1997). This can indicate an ambush hunting type, with short pursuit and violent impact with prey before the fatal slash (Argot, 2004 and references therein). This is another example where our methods would be helpful to determine the likelihood of different scenarios.

Not only can our general methods be useful for paleobiological studies, but also our results on free-fall hunting. The risk of free-falling hunting is too high to be used frequently by a predator. Any slight misalignment during the fall would produce a probability of lethal blunt trauma close to $2 \%$ and, in some cases, much larger (see Table 1). Therefore any adaptation to change body orientation during free fall would increase the chances of success. In the case of leopards, the tail is probably very useful to make small adjustments of body orientation during free-fall hunting. In all the videos studied here, it is possible to see that leopards make extremely fast tail movements during the fall. The role of the tail to change body orientation in mid-air was already determined in cats (Edwards, 1986; Fredrickson, 1989; Walker, Vierck and Ritz, 1998), primates (Dunbar, 1988), rodents (Bartholomew and Caswell, 1951) and lizards (Libby et al., 2012; Gillis, Kuo and Irschik, 2013). Moreover, wind tunnel tests illustrate that the fur of a felid's tail (Acynonix jubatus) exhibits significant aerodynamic drag, and numerical simulations revealed that the tail could impart significant angular impulse on the body by using these aerodynamic forces (Patel, 2015). The cheetah tail (and probably the leopard's tail too) could be employed effectively to stabilize rapid maneuvers even in mid-air (Libby et al., 2012 and references therein; Patel, 2015). Predatory vertebrates with arboreal adaptations, large tails, and some capability to generate significant aerodynamical forces are good candidates to present free-fall hunting behavior. Therefore, we can consider that freefall hunting would be unlikely in extinct felids with short tails like those of the genera Smilodon, Homotherium, or Megantereon (Turner, 1997). Better candidates are felids and nimravids with a more arboreal design and long tails as Pseudalurus, Proailurus, and even Hoplophoneus (Turner, 1997). Moreover, from equations 2, 4, 6, and 7, it is possible to see that, if everything is equal, the probability of lethal blunt trauma increases with the prey's body mass. Therefore, for extinct predators that hunted prey larger than themselves, as it was suggested for Smilodon and several other sabretoothed felids (Turner, 1997), this behavior would be too dangerous.

Another very suggestive paleobiological implication is related to theropod dinosaurs and the origin of flight in birds. Our results imply that any adaptation enhancing the capability for righting and turning in mid-air during free-falling hunting would help avoid accidental collisions with a high probability of lethal blunt trauma. It was proposed that small theropods like Velociraptor, an agile, $20-\mathrm{kg}, 1.5-\mathrm{m}$-tall biped with an active tail, might have been capable of aerial acrobatics beyond even those displayed by present-day arboreal lizards (Libby et al., 2012). The origin of avian flight required elongation of the theropods' forelimbs and the development of feathers from body integuments. Those features would be useful to generate aerodynamical forces with the forelimbs giving to some small theropods great control of body orientation and speed in mid-air (Dudley et al., 2007; Chaterjee and Templin, 2012). It was also suggested that among other biomechanical arguments, the climbing adaptations of maniraptorans such as Sinornithosaurus - including elongated forelimbs, swivel wrist joint, and recurved claws for grasping trunks, a caudally directed pubis, and a supporting stiffened tail end give support to the arboreal hypothesis of the origin of flight (Chaterjee and Templin, 2012). It was suggested that maniraptorans like Caudipteryx, Protarchaeopteryx, and Sinornithosaurus might have had small proto-wings that most probably evolved as a safety device for arbore- 
al maneuvering to increase drag and reduce the impact of their fall (Chaterjee and Templin, 2012). All these features lead to the speculative scenario where some maniraptorans used free-fall hunting. Moreover, such behavior would be a candidate of selective pressure that in some stage improved the aerodynamical performance of wings and feathers, leading to the evolution of flying birds.

To assess the risk of predation in different situations as we did here could be useful to understand the predatory behavior of living animals. The methods presented here can also help assess the feasibility of paleobiological hunting scenarios proposed for extinct felids or other vertebrates.

\section{References}

ACID. 2018. Leopardo Emboscando Impala Desde Un Arbol. https://www.youtube.com/watch?v=1qolC9Gp_cY

Ackermann, J. and Redig, P. 1997. Surgical repair of elbow luxation in raptors. Journal of Avian Medicine and Surgery 11(4):247-254.

Alexander, R. M. 1989. Dynamics of dinosaurs and other extinct giants. Columbia University Press.

Alexander, R. M. 2003. Principles of animal locomotion. Princeton University Press. https://doi. org/10.1515/9781400849512

Argot, C. 2004. Functional-adaptive features and palaeobiologic implications of the postcranial skeleton of the late Miocene sabretooth borhyaenoid Thylacosmilus atrox (Metatheria). A/cheringa 28(1):229-266. https://doi. org/10.1080/03115510408619283

Bailey, T. N. 2005. The African leopard: ecology and behavior of a solitary felid. Caldwell.

Balme, G., Hunter, L., and Slotow, R. O.B. 2007. Feeding habitat selection by hunting leopards Panthera pardus in a woodland savanna: prey catchability versus abundance. Animal Behaviour 74(3):589-598. https://doi. org/10.1016/j.anbehav.2006.12.014

Bartholomew, G.A. and Caswell, H. H. 1951. Locomotion in kangaroo rats and its adaptive significance. Journal of Mammalogy 32(2):155-169. https://doi. org/10.2307/1375371

Bedrosian, B. E. and Pierre, A. M. S. 2007. Frequency of injuries in three raptor species wintering in northeastern Arkansas. The Wilson Journal of Ornithology 119(2):296-298. https://doi.org/10.1676/05-124.1

Bertram, B. C. R. 1982. Leopard ecology as studied by radio tracking. Symposiums of the Zoological Society, London 49:341-352.

Bothma, J. D. P. and Le Riche, E. A. N. 1984. Aspects of the ecology and the behaviour of the leopard Panthera pardus in the Kalahari Desert. Koedoe 27(2):259-279. https://doi. org/10.4102/koedoe.v27i2.585

Bothma, J. D. P. and Le Riche, E. A. N. 1989. Evidence of a new flexible hunting technique in Kalahari leopards. South African Journal of Wildlife Research 19(2):57-60.

Bothma, J.D. P., Van Rooyen, N., and Le Riche, E. A. N. 1997. Multivariate analysis of the hunting tactics of Kalahari leopards. Koedoe 40(1):41-56. https://doi.org/10.4102/ koedoe.v40i1.262

Brown, C., Balisi, M., Shaw, C. A., and Van Valkenburgh, B. 2017. Skeletal trauma reflects hunting behaviour in extinct sabre-tooth cats and dire wolves. Nature Ecology \&
Evolution 1(5):1-7. https://doi.org/10.1038/s41559-0170131

Carpenter, K. 1997. Agonistic behavior in pachycephalosaurs (Ornithischia, Dinosauria); a new look at head-butting behavior. Rocky Mountain Geology 32(1):19-25.

Chatterjee, S. and Templin, R. J. 2012. Palaeoecology, aerodynamics, and the origin of avian flight; pp. 585-612 in Talent, J. A. (eds.) Earth and Life. Springer, Dordrecht. https://doi.org/10.1007/978-90-481-3428-1_18

Creel, S. and Creel, N. M. 2002. The African wild dog: behavior, ecology, and conservation. Princeton University Press. https://doi.org/10.1515/9780691207001

Cuff, A. R., Sparkes, E. L., Randau, M., Pierce, S. E., Kitchener, A. C., Goswami, A., and Hutchinson, J. R. 2016. The scaling of postcranial muscles in cats (Felidae) I: forelimb, cervical, and thoracic muscles. Journal of Anatomy 229(1):128-141. https://doi.org/10.1111/joa.12477

Dudley, R., Byrnes, G., Yanoviak, S. P., Borrell, B., Brown, R. M., and McGuire, J.A. 2007. Gliding and the functional origins of flight: biomechanical novelty or necessity? Annual Review of Ecology, Evolution, and Systematics 38:179-201. https://doi.org/10.1146/annurev.ecolsys.37.091305.110014

Dunbar, D. C. 1988. Aerial maneuvers of leaping lemurs: The physics of whole-body rotations while airborne. American Journal of Primatology 16(4):291-303. https://doi. org/10.1002/ajp.1350160402

Edwards, M. H. 1986. Zero angular momentum turns. American Journal of Physics 54(9):846-847. https://doi. org/10.1119/1.14429

Ercoli, M. D., Prevosti, F.J., and Alvarez, A. 2012. Form and function within a phylogenetic framework: locomotory habits of extant predators and some Miocene Sparassodonta (Metatheria). Zoological Journal of the Linnean Society 165(1):224-251. https://doi.org/10.1111/j.10963642.2011.00793.x

Farlow, J. O., Smith, M. B., and Robinson, J. M. 1995. Body mass, bone "strength indicator" and cursorial potential of Tyrannosaurus rex. Journal of Vertebrate Paleontology 15(4):713-725. https://doi.org/10.1080/02724634.1995. 10011257

Frank, M., Jobski, O., Bockholdt, B., Grossjohann, R., Stengel, D., Ekkernkamp, A., and Hinz, P. 2012. When backyard fun turns to trauma: risk assessment of blunt ballistic impact trauma due to potato cannons. International Journal of Legal Medicine 126(1):13-18. https://doi. org/10.1007/s00414-011-0552-y

Fredrickson, J.E. 1989. The tail-less cat in free-fall. The Physics Teacher 27(8):620-624. https://doi. org/10.1119/1.2342893

Frey, R., Volodin, I. A., Volodina, E. V., Efremova, K. O., Menges, V., Portas, R., Melzheimer, J., Fritsch, G., Gerlach, C., and von Dörnberg, K. 2020. Savannah roars: The vocal anatomy and the impressive rutting calls of male impala (Aepyceros melampus) - highlighting the acoustic correlates of a mobile larynx. Journal of Anatomy 236(3):398424. https://doi.org/10.1111/joa.13114

Galton, P. M. 1971. A primitive dome-headed dinosaur (Ornithischia: Pachycephalosauridae) from the Lower Cretaceous of England and the function of the dome of pachycephalosaurids. Journal of Paleontology 45(1):4047.

Gillis, B., Kuo, G., and Irschick, D. 2013. The impact of tail loss on stability during jumping in green anoles (Anolis carolinensis). Physiological and Biochemical Zoology 86(6):680689. https://doi.org/10.1086/673756

Goin, F. J. and Pascual, R. 1987. News on the biology and taxonomy of the marsupials Thylacosmilidae [Late Terciary 
of Argentina]. Anales de la Academia Nacional de Ciencias Exactas, Físicas y Naturales de Buenos Aires 39.

Hart, J. A., Katembo, M., and Punga, K. 1996. Diet, prey selection and ecological relations of leopard and golden cat in the Ituri Forest, Zaire. African Journal of Ecology 34(4):364379. https://doi.org/10.1111/j.1365-2028.1996.tb00632.x

Hart, L. A., Wreford, E. P., Brown, M., and Downs, C. T. 2018. Hunting flight speeds of five southern African raptors. Ostrich 89(3):251-258. https://doi.org/10.2989/0030652 5.2018.1455754

Hunter, J. A. 1952. Hunter. Hamish Hamilton, UK.

Janis, C. M., Figueirido, B., DeSantis, L., and Lautenschlager, S. 2020. An eye for a tooth: Thylacosmilus was not a marsupial "saber-tooth predator". Peer] 8:e9346. https://doi. org/10.7717/peerj.9346

Jenny, D. and Zuberbühler, K. 2005. Hunting behaviour in West African forest leopards. African Journal of Ecology 43(3):197200. https://doi.org/10.1111/j.1365-2028.2005.00565.x

Krauss, D. A. and Robinson, J. M. 2013. The Biomechanics of a plausible hunting strategy for Tyrannosaurus rex; pp. 250-262 in Parrish, J. M., Molnar, R. E., Currie, P. J., Koppelhus, E. B. (Eds.), Tyrannosaurid Paleobiology. Indiana Univerity Press, Bloomington.

Kruuk, H. and Turner, M. 1967. Comparative notes on predation by lion, leopard, cheetah and wild dog in the Serengeti area, East Africa. Mammalia 31(1):1-27. https://doi. org/10.1515/mamm.1967.31.1.1

Kruger Sightings. 2019. Leopard jumps on impala from tree. https://www.youtube.com/watch?v=vQEptisMtyw

Leopard - Cheetah Channel. 2017. Leopard jumps from tall tree to ambush prey. https://www.youtube.com/ watch? $v=$ LEOad2sCKds\&t=3s

Libby, T., Moore, T. Y., Chang-Siu, E., Li, D., Cohen, D. J., Jusufi, A., and Full, R.J 2012. Tail-assisted pitch control in lizards, robots and dinosaurs. Nature 481(7380):181-184. https://doi.org/10.1038/nature10710

Mukherjee, S. and Heithaus, M. R. 2013. Dangerous prey and daring predators: a review. Biological Reviews 88(3):550563. https://doi.org/10.1111/brv.12014

Murza, G. L., Bortolotti, G. R., and Dawson, R. D. 2000. Handicapped American kestrels: needy or prudent foragers? Journal of Raptor Research 34(2):137-142.

Patel, A. 2015. Understanding the motions of the cheetah tail using robotics. PhD thesis University of Cape Town.

Riggs, E. S. 1934. A new marsupial saber-tooth from the Pliocene of Argentina and its relationships to other South American predacious marsupials. Transactions of the American Philosophical Society 24(1):1-32. https://doi. org/10.2307/3231954

Roth, A. J., Jones, G. S., and French, T. W. 2002. Incidence of naturally-healed fractures in the pectoral bones of North American accipiters. Journal of Raptor Research 36(3):229-230.
Schaller, G. B. 1972. The Serengeti lion: a study of predatorprey relations. University of Chicago Press, Chicago.

Shazal. 2014. Unbelievable Leopard Kill Norman Carr SafariZambia. https://www.youtube.com/watch?v=RBasnLt5d50

Shock wave. 2019. Surprise 'Leopard jump' and attack from the tree and kill very fast. https://www.youtube.com/ watch?v=ebtR8hXatQ4

Stander, P.E., Haden, P.J., Kaqece, I. I., and Ghau, I. I. 1997. The ecology of asociality in Namibian leopards. Journal of Zoology 242(2):343-364. https://doi. org/10.1111/j.1469-7998.1997.tb05806.x

Stein, A. B. and Hayssen, V. 2013. Panthera pardus (Carnivora: Felidae). Mammalian Species 45(900):30-48. https://doi. org/10.1644/900.1

Sturdivan, L. M., Viano, D. C., and Champion, H. R. 2004. Analysis of injury criteria to assess chest and abdominal injury risks in blunt and ballistic impacts. Journal of Trauma and Acute Care Surgery 56(3):651-663. https:// doi.org/10.1097/01.TA.0000074108.36517.D4

Sunquist, M. and Sunquist, F. 2002. Wild cats of the world. University of Chicago Press. https://doi.org/10.7208/chicago/9780226518237.001.0001

Sunquist, M. E. and Sunquist, F. C. 2009. Family Felidae (cats); pp. 54-168 in Wilson, D. E., Mittermeier, R. A. (Eds.), Handbook of the mammals of the world, Vol. 1. Lynx Editions, Barcelona.

Tucker, V.A. 1998. Gliding flight: speed and acceleration of ideal falcons during diving and pull out. Journal of Experimental Biology 201(3):403-414. https://doi.org/10.1242/ jeb.201.3.403

Tucker, V. A., Cade, T. J., and Tucker, A. E. 1998. Diving speeds and angles of a gyrfalcon (Falco rusticolus). Journal of Experimental Biology 201(13):2061-2070. https://doi. org/10.1242/jeb.201.13.2061

Turner, A. 1997. The big cats and their fossil relatives: an illustrated guide to their evolution and natural history. Columbia University Press.

Van Valkenburgh, B. 2009. Costs of carnivory: tooth fracture in Pleistocene and Recent carnivorans. Biological Journal of the Linnean Society 96(1):68-81. https://doi. org/10.1111/j.1095-8312.2008.01108.x

VanValkenburgh, B. and Hertel, F. 1993. Tough times at La Brea: tooth breakage in large carnivores of the late Pleistocene. Science 261(5120):456-459. https://doi. org/10.1126/science.261.5120.456

Vogel, S. 2009. Glimpses of creatures in their physical worlds. Princeton University Press. https://doi. org/10.1515/9781400833863

Walker, C., Vierck Jr, C. J., and Ritz, L. A. 1998. Balance in the cat: role of the tail and effects of sacrocaudal transection. Behavioural Brain Research 91(1-2):41-47. https:// doi.org/10.1016/S0166-4328(97)00101-0 
Appendix 1. Data collected from videos

\begin{tabular}{l|c|c|c|c|c}
\hline \multicolumn{1}{c|}{ Video } & $\begin{array}{c}\text { Leopard - Cheetah } \\
\text { Channel 2017 }\end{array}$ & $\begin{array}{c}\text { Kruger Sightings } \\
2019\end{array}$ & $\begin{array}{c}\text { ACID } \\
2018\end{array}$ & $\begin{array}{c}\text { Shock wave } \\
2019\end{array}$ & $\begin{array}{c}\text { Shazal } \\
2015\end{array}$ \\
\hline $\begin{array}{l}\text { Time of the fall (s), measured } \\
\text { from videos }\end{array}$ & 0.7 & 0.5 & 0.8 & 0.7 \\
\hline $\begin{array}{l}\text { Initial Height to the ground (m), } \\
\text { measured from videos }\end{array}$ & 3.51 & 2.84 & 3.88 & 3.39 & 4.15 \\
\hline $\begin{array}{l}\text { Speed at the collision (m/s), } \\
\text { estimated from traveled distance }\end{array}$ & 7.2 & 6.2 & 7.7 & 7.0 & 8.0 \\
\hline
\end{tabular}

